\title{
Diversidade Cultural, \\ Patrimônio Cultural Material \\ e Cultura Popular: a Unesco e a Construção de um \\ Universalismo Global
}

Elder Patrick Maia Alves ${ }^{1}$

Resumo: Este artigo procura situar o advento e a operacionalização de uma formação discursiva responsável pela emergência de um novo universalismo global. Tal universalismo traz como imperativo ético-moral a defesa e a promoção de valores como a diversidade cultural. Para compreender as implicações políticas e culturais desse universalismo, este trabalho elege como eixo empírico a atuação da Organização das Nações Unidas Para Educação, a Ciência e a Cultura (UNESCO), destacando as ações dessa organização na coordenação e dinamização de um trânsito simbólico e discursivo transnacional envolvendo governos, organizações não-governamentais e grupos políticos.

Palavras-chave: Universalismo global; UNESCO; trânsito simbólico; diversidade cultural; patrimônio imaterial e cultura popular.

1. Introdução

ste trabalho tem como propósito central desvelar a atuação da Organização das Nações Unidas para Educação, a Ciência e a Cultura (Unesco) na coordenação específica de um trânsito simbólico e discursivo, envolvendo governos, organizações da sociedade civil global e organismos transacionais. Essa coordenação permitiu à Unesco, entre outros aspectos, criar os principais instrumentos jurídicos transnacionais responsáveis pelo disciplinamento e o tratamento jurídico-político de temas e questões envolvendo a cultura popular e/ ou tradicional, o patrimônio cultural imaterial e as novas relações entre cultura e desenvolvimento.

A rigor, o próprio trânsito discursivo e simbólico aludido, assim como a atuação mais incisiva da Unesco no que tange aos assuntos culturais nas últimas décadas, bem como as novas ações e programas de políticas culturais adotadas por diversos governos nos mais variados contextos, faz parte de uma configuração
Recebimento:

01.2010

Aprovado:

10.2010
1. Graduado em Ciências Sociais (licenciatura e bacharelado) pela Universidade Federal da Bahia (UFBA); mestre e doutor em Sociologia pela Universidade de Brasília (UnB); professor adjunto I de Sociologia do Instituto de Ciências Sociais (ICS) e professor do Programa de Pós-Graduação em Sociologia (PPGS) na Universidade Federal de Alagoas (UFAL); pesquisador da Fundação de Amparo à Pesquisa do Estado de Alagoas (FAPEAL). epmaia@hotmail. com 
2. O trabalho de pesquisa resultou na tese de doutorado $A$ economia simbólica da cultura popular sertanejo-nordestina, desenvolvida junto ao Programa de Pós-Graduação em Sociologia da Universidade de Brasília (PPG-SOLUnB), iniciada em 2005 e concluída em 2009.
(Elias, 1991: 122) político-simbólica mais abrangente. Sua trama passou a ser confeccionada a partir do recrudescimento do processo de industrialização do simbólico (Canclini, 2003: 114) no decurso da década de sessenta do século passado e, como tal, impactou no modo de perceber e normatizar as relações entre a produção simbólico-cultural, a economia e a política. Para compreender determinados aspectos da trama dessa configuração e, por conseguinte, para que o objetivo desse trabalho fique patente é preciso situar as indagações aqui contidas no escopo geral do processo de pesquisa do qual elas brotaram. O que se segue é parte constitutiva de um trabalho de investigação realizado nos últimos quatro anos, intitulado A economia simbólica da cultura popular sertanejo-nordestina ${ }^{2}$. O trabalho de pesquisa abrigou como eixo temático as transformações ocorridas no âmbito da produção simbólico-cultural contemporânea, notadamente no que diz respeito às novas faces e fases do processo de industrialização do simbólico com as políticas culturais públicas. Diante desse eixo temático, a pesquisa buscou compreender as interfaces entre determinadas políticas culturais públicas e o advento de uma nova formação discursiva (o repertório discursivo Unesco) para a estruturação de um mercado de bens e serviços culturais assaz específico, ancorado fundamentalmente no valor social conferido à categorias como tradição e "autenticidade".

2. A Unesco e o advento de um novo universalismo global: diversidade, cultura e desenvolvimento

As muitas dimensões pelas quais o conceito de cultura penetrou o debate e a problemática do desenvolvimento durante a segunda metade do século XX se imbricaram inteiramente nos últimos anos. Essa interpenetração ensejou novos usos da categoria cultura e uma série de envolvimentos políticos por parte de vastos segmentos da sociedade civil global e, por conseguinte, de alguns organismos transnacionais, como a Unesco. Essa organização passou a ser, sobretudo a partir dos anos noventa, uma espécie de núcleo global das tensões envolvendo cultura e desenvolvimento. A Unesco passou a capitanear as discussões realizadas em âmbito mundial no que diz respeito a um conjunto de ações e propostas de regulamentação, definição e normatização da categoria cultura em face das profundas transformações ocorridas no final do século XX. Mattelart sustenta que a cultura, como uma área de competência específica reivindicada pela Unesco, ganhou maior densidade institucional no decurso dos anos noventa, com a promulgação de inúmeros documentos de regulamentação: declarações, recomendações e convenções (Mattelart, 2005: 160).

A tensão central inscrita no seio da Unesco foi construída a partir da consolidação e do grande crescimento da demanda mundial por bens e serviços culturais, que resultou no aumento vertiginoso de alguns mercados culturais, como o fonográfico, o editorial e o cinematográfico. O crescimento desses mercados, 
que foram acompanhados do crescimento e da desregulamentação de alguns mercados nacionais, como o mercado financeiro, ocorreu simultaneamente à profusão de um conjunto de novas tecnologias da informação e de uma infinidade de multimídias. $\mathrm{O}$ advento desses meios, aliado às novas convergências digitais que conferiram ao processo de industrialização do simbólico uma nova dinâmica, intensificou ainda mais os fluxos informacionais e comunicacionais em todo o mundo. Todos esses processos concorreram para engendrar a chamada globalização cultural, que levou autores como Jameson a falar em explosão da cultura, segundo o autor, a sensação de que a cultura estaria em todos os lugares ao mesmo tempo (Jameson, 2006: 62).

O crescimento dos mercados culturais mundiais e a expansão dos fluxos simbólicos globais geraram a sensação generalizada de que o mundo estaria passando por um processo acelerado de homogeneização e padronização cultural (Mattelart, 2005: 89). Essa sensação decorreu, em certa medida, das profundas assimetrias existentes entre os principais pólos de produção simbólica (Estados Unidos e União Europeia), classificados como os centros exportadores de bens culturais, e os pólos de consumo (América Latina, África e Ásia), classificados como os centros de importação. A globalização cultural estaria, assim, potencializando as antigas e já profundas assimetrias da divisão internacional do trabalho cultural (Yudice, 2005).

Mattelart destaca que surge, a partir do início dos anos noventa do século passado, um grande apelo global à diversidade cultural e uma luta encarniçada das identidades regionais em meio à configuração da globalização cultural (Mattelart, 2005: 96). É em nome da preservação e promoção da diversidade e da identidade cultural que muitos estados nacionais e instituições transnacionais passaram a defender a elaboração e execução de novas políticas públicas de cultura. No entanto, como sustenta o próprio Mattelart, foi a consecução de uma rede global de defesa e promoção da diversidade e da identidade que produziu uma grande pressão junto aos governos nacionais (sobretudo os governos dos chamados países em desenvolvimento) e organismos transnacionais (BID e UNESCO), no sentido da adoção de novas políticas culturais que pudessem ressemantizar e ressignificar um conjunto de conceitos, como o conceito de exceção cultural (Mattelart, 2005: 102).

Em 1999, por exemplo, os países membros da União Europeia substituíram o conceito de exceção cultural pelo conceito de diversidade cultural. O principal argumento para efetivação dessa mudança foi elaborado segundo a justificativa de que o conceito de diversidade cultural seria mais afirmativo, conotando uma posição menos defensiva, embora naquele momento oferecesse pouca segurança jurídica, visto que não havia ainda um marco jurídico legal no âmbito do direito europeu e do direito internacional. Seis anos mais tarde, em 2005, 
a União Europeia, sob a liderança do Ministério da Cultura francês, lançou um programa de política cultural continental, assinado por 24 ministros europeus da cultura, com vistas a desenvolver um minucioso mapeamento cultural do continente, que possuía como objetivo central preservar e promover as diferenças culturais do continente, chamando atenção para as identidades culturais locais do mesmo. Essas ações, entre muitas outras em âmbito transcontinental e transnacional, conduziram à consecução progressiva de um novo universalismo, ancorado no grande valor atribuído à diferença e à diversidade cultural (Mattelart, 2005). Não obstante, para que essas categorias e conceitos compusessem uma espécie de amálgama ético-moral, ao longo das últimas duas décadas, foi necessário um grande trabalho de mobilização político-cultural. Em nome da defesa da diferença e da diversidade cultural foram criadas inúmeras instituições culturais e políticas (organizações nacionais ligadas a entidades da sociedade civil, organizações não-governamentais, locais, nacionais e transacionais, entidades de artistas, produtores culturais e governos em geral) empenhadas na luta pela defesa e promoção da identidade cultural e da diversidade cultural em âmbito local, nacional e transacional, desdobrada na luta pela defesa e promoção de diversas formas de reconhecimento identitário, como o sexual, étnico e racial. Essa extensa rede de organizações levou, na passagem do século XX para o século XXI, à constituição de coalizões globais de luta em defesa e promoção da identidade e da diversidade cultural espalhadas por todo mundo. A coalizão brasileira pela diversidade cultural foi criada em 2001.

As coalizões globais são modelos organizacionais da sociedade civil. Elas agem no sentido de pressionar os governos nacionais para que adotem medidas de defesa e promoção da identidade e da diversidade cultural. Nesse sentido, o principal objetivo das coalizões é criar as condições políticas que assegurem o cumprimento de resoluções e convenções, além de outros documentos, estabelecidos pelo sistema ONU, em particular pela Unesco. As coalizões possuem o caráter de observadoras permanentes no âmbito da Unesco, sem, contudo, ter poder de voto, mas com grande força de sensibilização político-cultural. De acordo com Mckee, em 2006 havia mais de 30 coalizões, que representavam mais de 200 organizações de profissionais da cultura: técnicos, consultores, gerentes, empresários, produtores culturais, artistas (cantores, músicos, atores, bailarinos, arranjadores, entre muitos outros), gestores públicos e políticos (Mckee, 2006: 23).

Os apelos à diversidade e à promoção das identidades locais foram potencializados em territórios como a América Latina, contextualmente marcados por uma grande heterogeneidade de línguas, crenças, costumes e tradições. No continente latino-americano o temor generalizado de uma unificação cultural fez com que as organizações profissionais de cultura, em parceria com os 
movimentos sociais, assumissem a tarefa de pressionar os governos locais e nacionais no sentido de realizar a defesa e promoção das identidades locais e regionais. Manuel Castells destaca que a luta latino-americana pelo direito à diversidade cultural deu ao tema da identidade, nesse continente, um poder extremamente mobilizador e politicamente muito eficaz (Castells, 2000: 77).

Não obstante, é preciso localizar com maior precisão empírica a montagem das coalizões globais pela diversidade cultural e pela identidade. Para tanto, é preciso situar o papel de agências transnacionais como a Unesco, pois foi em torno desta que essas coalizões ganharam operacionalidade política e densidade jurídica. A legitimação das reivindicações assumidas pelas coalizões globais passou também pelo crescimento da importância da área de cultura no interior da Unesco. Por isso, o aspecto central a partir do qual essas coalizões globais produziram um novo universalismo global diz respeito às lutas simbólicas travadas no interior de determinados governos e de agências transnacionais, como a Unesco, a qual passou a criar mecanismos jurídicos capazes de definir instrumentos de proteção e promoção da diversidade e da identidade. Não obstante, a definição desses novos instrumentos jurídicos passou por severas guerras simbólicas em torno da definição mais adequada (de acordo com os interesses de governos, empresas, agências transacionais e grupos culturais) das categorias de diversidade, identidade, criatividade, cultura e desenvolvimento. Essas lutas e disputas se cristalizaram com maior clareza por ocasião da votação da Declaração Universal sobre a Diversidade Cultural, em 2001, no âmbito da Unesco, e posteriormente, em 2005, quando da aprovação da Convenção Sobre a Proteção e a Promoção da Diversidade das Expressões Culturais. Ambas as votações e seus respectivos textos são resultado de um longo processo de normatização, oficialização e dilatação do conceito de cultura no âmbito da Unesco, desencadeado com maior vigor a partir dos anos setenta e recrudescido nos anos noventa do século passado, a partir das demandas políticas, econômicas e simbólicas que surgiram nas últimas décadas do século XX. As conferências de cultura realizadas pela Unesco, ao longo das décadas de setenta e oitenta, são exemplos de resultado do processo mencionado acima, a saber: a EUROCULT, realizada em Helsinque, em 1972; a ASIACULT, realizada em Jacarta, em 1973; a AFRICACULT, realizada em Accra; a AMERICACULT, realizada em Bogotá, em 1978; e ARABIACULT, realizada em Bagdá, em 1981; todas culminando na Conferência Mundial sobre Políticas Culturais (MUNDIALCULT), realizada na Cidade do México, em 1982, e atualizada na Conferência de Estocolmo sobre Políticas Culturais para o Desenvolvimento, em 1988.

Todas essas ações coordenadas pela Unesco tiveram como efeito prático a dilatação do conceito de cultura. Essa dilatação permitiu que o conceito de cultura e sua temática penetrassem o conceito e a temática do desenvolvimento. Essa 
dilatação, assim como a interpenetração entre os conceitos de cultura e desenvolvimento, é evidenciada nos dois documentos de maior relevância publicados pela Unesco, as duas convenções promulgadas nesta década: a Convenção para Salvaguarda do Patrimônio Cultural Imaterial, aprovada em 2003, e a Convenção sobre a Proteção e Promoção da Diversidade das Expressões Culturais, aprovada em 2005.

Embora a Convenção sobre a diversidade cultural tenha seu texto base, ou seja, sua declaração apresentada antes da Convenção para Salvaguarda do Patrimônio Cultural Imaterial, seu processo de votação e apresentação só foi concluído quatro anos mais tarde, em 2005. No dia 20 de outubro de 2005, durante a $33^{\text {a }}$ Conferência Geral da Unesco, os estados membros decidiram, com 148 votos a favor e apenas 2 votos contra, adotar a Convenção proposta para a Proteção e Promoção da Diversidade das Expressões Culturais. Embora o texto da convenção tenha sido rejeitado por apenas dois países, foram votos bastante significativos, pois se trataram dos votos dos Estados Unidos e Israel. Segundo esses países, a aprovação do texto da convenção, nas bases em que se apresentava, poderia incentivar, em vez de atenuar, algumas formas de nacionalismos violentos e fundamentalismos étnico-religiosos. Esses países, notadamente os Estados Unidos, quando da votação e aprovação da convenção, viviam os desdobramentos políticos do episódio bélico de 11 de setembro de 2001.

A Convenção significou, de maneira clara, pela primeira vez no âmbito do direito internacional, o reconhecimento, através de uma convenção ou tratado internacional, da natureza distinta dos bens e serviços culturais. O texto da Declaração Universal sobre a Diversidade foi aprovado, em 2001, por unanimidade. Esse texto tornou-se o documento preparatório para a realização e aprovação da Convenção, em 2005. A partir da aprovação do texto da declaração, a grande maioria dos estados membros defendiam que fosse atribuída à convenção o estatuto jurídico de tratado internacional, em uma instância jurídica com poder suficiente para garantir seu cumprimento. A convenção aprovada se tornou um instrumento jurídico de caráter internacional, com força de lei, criando compromissos, direitos e deveres. Ao contrário de outros instrumentos jurídicos, como, por exemplo, as declarações e recomendações que são destinadas à disseminação de ideias e valores, a convenção tem força de lei, pois cria, além do compromisso de cumprimento entre os países signatários, o compromisso de difusão e promoção. A convenção é considerada o instrumento jurídico mais poderoso e com maior eficácia jurídica no âmbito de um organismo transnacional.

3. Coordenadora da UNESCO no Brasil
Segundo Jurema Machado ${ }^{3}$, a Convenção para Proteção e Promoção da Diversidade das Expressões Culturais marca a consolidação de um conjunto de instrumentos jurídicos produzidos pela Unesco desde os anos setenta. O que atesta que, entre as áreas de atuação e competência da organização, a cultura é a que 
apresenta o maior número de regulamentações e dispositivos normativos. São sete convenções que, a partir de sete campos distintos, estão atravessadas pelo tema da diversidade como um eixo transversal e um valor universal (Machado, 2008). A coordenadora de cultura da Unesco no Brasil destaca, ainda, que as demais convenções, como a Convenção Para Salvaguarda do Patrimônio Cultural Imaterial (2003), complementam a Convenção Para Proteção e Promoção da Diversidade das Expressões Culturais, 2005. "Basta dizer que o sentido da preservação do patrimônio, seja material ou imaterial, não é outra senão preservar, proteger e promover a diversidade de registros materiais e imateriais da cultura" (Ibidem).

Percorrendo o texto da Convenção sobre a diversidade é possível verificar que há uma busca constante por um equilíbrio mínimo entre os direitos e as obrigações estabelecidos entre os países signatários. Machado defende que a Convenção não pode ser apenas um dispositivo para que os países signatários se valham de um recurso ético e jurídico destinado à proteção de seus mercados culturais, mas também que assumam o compromisso de implementação de políticas culturais regionais e, assim, assumam o compromisso de respeito para com a diversidade interna de suas próprias fronteiras, fomentando políticas culturais nesse sentido. Para tanto, assinala Machado, cabe principalmente aos países em desenvolvimento, que são aqueles que apresentam maior diversidade cultural, como o Brasil, um papel de destaque, sobretudo no que diz respeito à relação entre cultura e desenvolvimento no interior desses países.

O núcleo da relação entre cultura e desenvolvimento em países como o Brasil passa, necessariamente, pelo tenso equilíbrio entre diversidade cultural e desigualdade social. Para a consolidação e efetivação da diversidade como um direito, as relações entre cultura e desenvolvimento devem ser complementares, impulsionadas por políticas culturais desenvolvidas pelos governos de países como o Brasil, com profundas desigualdades sociais, que comprometem, portanto, o acesso e expansão da diversidade. As observações de Machado podem ser sintetizadas nos seguintes termos: como manter e promover a grande diversidade cultural de países como o Brasil diante das profundas desigualdades sociais? Em outros termos: como conciliar diversidade cultural, que é tratada no texto da própria convenção como o grande patrimônio da humanidade, com o desenvolvimento material, que passa pela expansão dos mercados culturais, regionais, nacionais e transnacionais e, por conseguinte, pelo consumo simbólico, tão relevante para a geração de trabalho, emprego e renda, aspectos estes diretamente ligados à redução das desigualdades sociais? Falando especificamente do Brasil, Machado assevera:

Há uma participação muito relevante dos municípios no financiamento da cultura, ou seja, nos investimentos e na manutenção, especialmente dos 
equipamentos culturais. Mais de $51 \%$ dos investimentos em cultura vêm dos municípios, o que nos leva a reforçar o princípio de que uma política da diversidade deve valorizar muito o local, cujo representante mais direto é o município (...). Concluindo, diria que para que o país, de fato, dê conseqüência prática a todas as teses em defesa da diversidade, dois aspectos me parecem fundamentais: incluir uma abordagem que privilegie o nível local, ou seja, as cidades, no âmbito das políticas culturais, bem como ter sempre em mente que estaremos, ainda por muito tempo, lidando com a produção da diversidade em um país que é culturalmente diverso, mas é, sobretudo, socialmente desigual. (Machado, 2008: 29)

Um dos aspectos destacados por Machado, o número significativo de convenções e instrumentos jurídicos na área da cultura no âmbito da Unesco, atesta o elevado grau de preocupação normativa com o tema da cultura. Esse aspecto, no entanto, está acompanhado de dissensões quanto à definição de conceitos centrais presentes nas convenções e demais instrumentos jurídicos, como diversidade, patrimônio imaterial, identidade, cultura e desenvolvimento. Essas dissensões são resultado de verdadeiras guerras simbólicas, guiadas por operações discursivas e interesses que formam novas formações discursivas (Foucault, 1986). A atuação do Brasil e de suas elites dirigentes à frente do Ministério da Cultura nos últimos anos expressa bem essas guerras simbólicas, que evidenciam as tensões e escaramuças que estruturam o trânsito simbólico e discursivo coordenado pela Unesco e dinamizado por países como o Brasil.

Gisele Dupin (servidora da Funarte e assessora da Secretaria da Identidade e da Diversidade Cultural - SID/MINC) sustenta que o Brasil foi um dos países membros da Unesco que mais se destacaram na aprovação da Convenção Sobre a Proteção e Promoção da Diversidade das Expressões Culturais. De acordo com Dupin, o Brasil foi decisivo, entre outros aspectos, para a alteração do nome da convenção. Após a Declaração Universal Sobre a Diversidade Cultural, decidiuse, no âmbito da Unesco e dos grupos de pressão em torno da mesma, que a declaração seria convertida em uma convenção. Em 2003, durante a Conferência Geral daquele ano, a convenção assumiu o título de Convenção Internacional para Preservação da Identidade Cultural. Durante a Conferência de 2004, a convenção passou a ser denominada de Convenção para a Proteção da Diversidade dos Conteúdos e das Expressões Artísticas. Por sugestão do Brasil, a convenção passou a se chamar, durante a Conferência Geral de 2005, Convenção sobre a Proteção e a Promoção da Diversidade das Expressões Culturais. Segundo Dupin, o governo brasileiro entendeu que o título anterior da convenção exprimia uma dicotomia discriminatória entre a cultura popular e a cultura erudita (DUPIN, 2008: 54).

A assessora da SID (Secretaria da Identidade e da Diversidade) enfatiza que o 
Ministério da Cultura do Brasil foi uma liderança significativa na organização da rede internacional de políticas culturais, que reúne os ministérios da cultura de mais de cinquenta países. Tal rede foi uma voz de grande relevo no processo de formação e aprovação da convenção sobre a diversidade e também integrou as coalizões mundiais destacadas por Mckee. Com efeito, diante desse envolvimento, assinala Dupin, o governo brasileiro criou, em 2003, a Secretaria da Identidade e da Diversidade Cultural, como experiência inédita em âmbito mundial, como um órgão do Ministério da Cultura de Estado incumbido de fomentar políticas no sentido de proteger e promover a diversidade cultural brasileira (Dupin, 2008).

Dupin assinala, ainda, que a principal atribuição da Secretaria da Identidade e da Diversidade é subsidiar a Secretaria de Políticas Culturais no processo de formulação das políticas culturais do Ministério da Cultura. A rigor, esses subsídios têm ocorrido no sentido de promover a diversidade a partir da inclusão de segmentos culturais antes excluídos das políticas oficiais, como os povos ciganos, as etnias indígenas, os grupos de cultura LGBT (lésbicas, gays, bissexuais, travestis e transexuais) e as culturas populares.

O envolvimento decisivo do governo brasileiro, através do Ministério da Cultura, no processo de aprovação da convenção sobre a diversidade se dá a partir de três interesses convergentes: a necessidade peremptória de incorporar, na estrutura da administração cultural, o valor universalista e universalizante da diversidade cultural; o interesse de inserir o tema da diversidade no espectro maior das políticas culturais para as culturas populares; e, por fim, o desejo de liderar um processo de formação discursiva que passa pela formação e consolidação de novas categorias nativas, como indústrias da criatividade, diversidade cultural, patrimônio imaterial, entre outras.

O primeiro interesse se cristalizou a partir da necessidade política dos dirigentes do Ministério da Cultura de legitimar suas ações junto às chamadas minorias culturais, que formam segmentos importantes no processo político que levou o presidente Luiz Inácio Lula da Silva às vitórias eleitorais de 2002 e 2006, e que se constituem como importantes grupos de pressão político-cultural. Já o segundo interesse diz respeito ao objetivo de conceder primazia às chamadas culturas populares, consideradas pelos dirigentes do Ministério da Cultura a grande fonte e repositório da diversidade cultural brasileira (MINC, 2006). O último interesse desse encadeamento aparece compondo um amálgama com os demais. Ao estreitar o diálogo com as organizações e grupos de pressão político-culturais ligados à cultura popular e às expressões tradicionais, o governo brasileiro, à frente do Ministério da Cultura, corroborou para inscrever na agenda das discussões culturais mundo afora a relevância simbólica e econômica de temas como a diversidade cultural, o que o permitiu, a partir da atuação de dirigentes como 
o ex-ministro Gilberto Gil, imprimir certa liderança junto à UNESCO, no decurso do processo de elaboração e legitimação das convenções.

Esses interesses percorrem direções específicas, mas convergem em duas entradas principais: a primeira no sentido de fomentar ações e programas para as culturas populares com vistas a inseri-las no panorama geral das relações entre cultura e desenvolvimento, escavando determinados mercados capazes de criar trabalho, emprego e renda para produtores, artistas, técnicos trabalhadores da cultura ligados às chamadas culturas populares. Por isso, o Ministério da Cultura sugeriu a mudança no título da convenção sobre a diversidade, alegando uma oposição entre popular e erudito. O objetivo seria desfazer, no título da convenção, qualquer alusão a essa oposição, o que permitiria ao órgão lançar mão de um tratado internacional como justificativa para desenvolver ações voltadas às expressões artísticas populares. Ações que, entre outros aspectos, veem a cultura popular como produtora de bens e serviços simbólicos para determinados mercados culturais, sedimentando o entendimento de que a diversidade, além de ser um fator de riqueza simbólica, pode ser também um fator de riqueza material.

A segunda entrada aludida acima decorre também do fato de que o apreço à cultura popular, revelado em ações e programas em diferentes órgãos da administração cultural, legitima o Ministério da Cultura frente a importantes segmentos artístico-intelectuais, que veem na cultura popular o núcleo mais candente e representativo da identidade nacional (MINC, 2006). Essa legitimação passa pelo reforço do entendimento de que a cultura popular reúne as formas mais "autênticas" das expressões e manifestações da identidade cultural de uma dada coletividade. Tal entendimento foi retomado e atualizado dentro do ambiente de emergência da globalização cultural, que deu origem a um novo universalismo contemporâneo, ancorado em um grande apelo global à diversidade (Mattelart, 2005).

Esse entendimento revela, por seu turno, que a Convenção sobre a Proteção e Promoção da Diversidade das Expressões Culturais e, ainda mais, a Convenção para Salvaguarda do Patrimônio Cultural Imaterial são instrumentos normativos informados por um conceito de cultura popular produzido pelas elites intelectuais e científicas latino-americanas, que entendem a cultura popular, como se percebe a partir do caso brasileiro, como as expressões e criações estéticas e artísticas de uma determinada coletividade. São essas expressões os demarcadores da identidade, que devem ser objeto de proteção e promoção, pois guardam e produzem a diversidade cultural, considerada o grande patrimônio da humanidade (Unesco, 2005).

A nova rede semântica que emerge dentro das fronteiras do trânsito simbólico 
e discursivo coordenado pela Unesco traz consigo também uma associação estreita entre o registro da diversidade simbólica e da diversidade biológica. Ao longo dos anos noventa, os temas da diversidade cultural e natural-biológica passaram a integrar o mesmo repertório discursivo acionado e manejado pela Unesco. A aproximação dessas grades temáticas aparece, por exemplo, na Conferência Intergovernamental sobre Políticas Culturais para o Desenvolvimento, realizada em Estocolmo, em 1988, onde a organização defende um equilíbrio entre os ecossistemas culturais tal qual ocorre entre os ecossistemas naturais. Na Conferência Geral que promulgou a Declaração Universal sobe a Diversidade Cultural, em 2001, a Unesco declarou ser a diversidade cultural tão vital para o gênero humano quanto a biodiversidade na ordem dos seres vivos (Unesco, 2003).

O conceito de diversidade cultural entrou na Unesco pela porta da frente. É a conclusão de um processo que surgiu no limiar da primeira crise do petróleo e da constatação da falência das estratégias de modernização/desenvolvimento. Em 1972, a Conferência das Nações Unidas sobre o Meio Ambiente e o Desenvolvimento, em Estocolmo, associa o tema da defesa da biodiversidade ao da diversidade cultural, todas duas realidades ameaçadas pelas lógicas predatórias e desiguais do modelo de crescimento ocidental, impulsionado pelo consumo excessivo de recursos naturais como bens materiais (Mattelart, 2005: 104).

3. Patrimônio cultural imaterial e cultura popular: tradição, diversidade e "autenticidade"

Esse movimento de aproximação semântica entre essas duas ordens de diversidade pode ser iluminado a partir da chave geral em que o tema da diversidade é inscrito, qual seja, a progressiva inserção do tema das culturas populares e tradicionais nas publicações, conferências, recomendações e convenções da Unesco. No decurso dos anos oitenta, a organização sedimentou o entendimento de que as culturas tradicionais e populares representavam o elo mais frágil face aos processos predatórios de industrialização e urbanização.

Um dos pontos de justificação que abre a Recomendação sobre a Salvaguarda da Cultura Tradicional e Popular, publicada durante a $25^{\text {a }}$ Conferência Geral da Unesco, em 1989, diz o seguinte: "Reconhecendo a extrema fragilidade de certas formas de cultura tradicional e popular e, particularmente, de seus aspectos correspondentes à tradição oral, bem como o perigo de que esses aspectos se percam" (Unesco, 1989). Os dois pontos subsequentes de justificação seguem a mesma direção: "Destacando a necessidade de reconhecer a função da cultura tradicional e popular em todos os países, e o perigo que corre em face de outros múltiplos fatores; considerando que os governos deveriam desempenhar papel 
decisivo na salvaguarda da cultura tradicional e popular e atuar o quanto antes" (Unesco, 1989). O temor quanto ao desaparecimento da cultura popular aparece de maneira mais clara nos parágrafos que tratam da salvaguarda e difusão da mesma.

A conservação se refere à proteção das tradições vinculadas à cultura tradicional e popular de seus portadores, segundo o entendimento de que cada povo tem direitos sobre sua cultura e de que sua adesão a essa cultura pode perder o vigor sob a influência da cultura industrializada difundida pelos meios de comunicação de massa. Por isso, é necessário adotar medidas para garantir do Estado o apoio econômico das tradições vinculadas à cultura tradicional e popular, tanto no interior das comunidades que as produzem quanto fora delas. (...) Deve-se sensibilizar a população para a importância da cultura tradicional e popular como elemento da identidade cultural. Para que se tome consciência do valor da cultura tradicional e popular e da necessidade de conservá-la, é essencial proceder a uma ampla difusão dos elementos que constituem esse patrimônio cultural. Numa difusão desse tipo, contudo, deve-se evitar toda deformação a fim de salvaguardar a integridade das tradições (Unesco, 1989).

A Recomendação para a Salvaguarda da Cultura Tradicional e Popular, embora não tenha eficácia legal no âmbito do direito internacional, cumpriu a função de instrumento de disseminação de ideias e valores. Como tal, tanto as medidas de sensibilização presentes no texto, quanto o conceito de cultura tradicional e popular definido na recomendação da Unesco de 1989, informaram sobremaneira as duas convenções da Unesco assinadas pelos países membros nesta década. A Recomendação para Salvaguarda da Cultura Tradicional e Popular define a cultura tradicional e popular nos seguintes termos:

A cultura tradicional e popular é um conjunto de criações que emanam de uma comunidade cultural fundada na tradição, expressas por um grupo ou por indivíduos e que reconhecidamente respondem às expectativas da comunidade enquanto expressão de sua identidade cultural e social; as normas e os valores se transmitem oralmente, por imitação ou de outras maneiras. Suas formas compreendem, entre outras, as línguas, a literatura, a música, a dança, os jogos, a mitologia, os rituais, o artesanato, a arquitetura e outras artes (Unesco, 1989).

A definição acima abriga dois registros conceituais, ambos incorporados e atualizados nas duas convenções celebradas pela Unesco nesta década. O primeiro registro conceitual aproxima-se bastante da definição antropológica de cultura, ou seja, a cultura como uma totalidade de normas, valores, crenças e tradições de uma determinada coletividade, que porta uma identidade específica. Esse 
registro aparece na primeira parte da definição acima, até o primeiro ponto de continuação. Já o segundo registro aparece a partir do ponto de continuação. Opera segundo uma definição de cultura popular bastante próxima àquela produzida pelos grupos político-culturais de intelectuais-artistas brasileiros durante os anos cinquenta e sessenta, que construíram uma espécie de estatuto social da "pureza" e da "autenticidade" 4 , e que de resto aparece entre as elites intelectuais e artísticas latino-americanas. Tal registro confere ênfase às formas de expressão e manifestações artístico-estéticas de uma determinada coletividade, como a própria definição da Unesco apresenta: "suas formas compreendem, entre outras, a linguagem, a literatura, a música, a dança, os jogos, a mitologia, os rituais, os costumes, o artesanato, a arquitetura e outras artes" (Unesco, 1989).

Nota-se que a definição, levando-se em conta os dois registros destacados, não incorpora, tal como ocorre nos Estados Unidos, Inglaterra e alguns países da Europa, os chamados meios de comunicação de massa, que integram as chamadas indústrias culturais, nem tampouco as novas tecnologias digitais. De um modo geral, as declarações, convenções e recomendações sobre a diversidade cultural, o patrimônio cultural imaterial e as culturas tradicionais e populares abrigam, cada um a sua maneira, certo desconforto e uma dificuldade de compatibilizar os conteúdos e expressões das chamadas culturas tradicionais e populares com as novas tecnologias digitais de comunicação e informação.

Todos esses documentos, refletindo as demandas e os interesses dos grupos político-culturais de pressão, buscam fugir do conceito "restrito" de cultura baseado nas chamadas artes eruditas e, por outro lado, buscam salvaguardar a diversidade, a cultura tradicional e popular e o patrimônio imaterial das chamadas indústrias culturais e dos efeitos de massificação atribuídos a essas últimas. Esse difícil equilíbrio engendrou toda sorte de remanejamentos conceituais e práticas discursivas no ambiente da Unesco e, por conseguinte, engendrou uma série de tensões. A rigor, essas tensões são resultado das lutas pela definição mais legítima do significado de cultura tradicional e popular, de patrimônio cultural imaterial e de diversidade cultural.

Entende-se por patrimônio cultural imaterial as práticas, representações, expressões, conhecimentos e técnicas - junto com os instrumentos, objetos, artefatos e lugares culturais que lhe são associados - que as comunidades, os grupos e, em alguns casos, os indivíduos, reconhecem como parte integrante do seu patrimônio imaterial. Este patrimônio cultural imaterial, que se transmite de geração em geração, é constantemente recriado por grupos em função de seu ambiente, de sua interação com a natureza, gerando um sentimento de identidade e continuidade e contribuindo assim para promover o respeito à diversidade cultural e a criatividade humana. 0 patrimônio imaterial, como foi definido acima, se manifesta nos seguintes
4. A formação desse estatuto refere-se a um longo processo que atravessa a estrutura da modernização cultural no Brasil, no que toca especificamente a mobilização das energias políticas e estéticas de diversas gerações de intelectuais e artistas brasileiros. Esses parâmetros foram, invariavelmente, atribuídos à experiência telúrica e às criações estéticoartísticas existentes no mundo rural, notadamente no sertão nordestino, para onde as gerações de intelectuais e artistas dirigiram o olhar desde o final do século XIX até a contemporaneidade sempre que acalentam encontrar elementos que demonstrem com segurança os substratos últimos da identidade nacional. Assim, a formação desse estatuto passa, direta e indiretamente, pelos impactos e atuação da geração de 1870 , na figura de um autor como Silvio Romero; aparecendo com vigor no movimento regionalista de 1930, na obra de autores como Graciliano Ramos e Rachel de Queiroz; passando pelo Movimento Folclórico, na atuação e pesquisas de autores como Mário de Andrade e Câmara Cascudo; encontrando grande ressonância nos movimentos 
político-culturais dos anos cinqüenta e sessenta do século XX, como o Teatro de Arena, o CPC da UNE, o Cinema Novo, entre outros. campos: a) tradições e expressões orais; incluindo o idioma como veículo do patrimônio cultural imaterial; b) expressões artísticas; c) práticas sociais, ritos e atos festivos; d) conhecimentos e práticas relacionadas à natureza e ao universo; d) técnicas artesanais tradicionais (Unesco, 2003).

A definição acima consta no $2^{\circ}$ artigo da Convenção para Salvaguarda do Patrimônio Cultural Imaterial da Unesco, celebrada em 2003. A definição é bastante ampla, mas novamente os dois registros destacados antes aparecem, com uma ênfase no registro que vê a cultura tradicional e popular a partir da lente das criações, expressões e manifestações artístico-estéticas de uma determinada coletividade. Os campos em que se manifesta o patrimônio cultural imaterial deixam a ênfase nesse registro bastante evidente: expressões artísticas; práticas sociais, rituais e atos festivos; conhecimentos e práticas relacionados à natureza e ao universo; técnicas artesanais tradicionais. Ou seja, bastante semelhante à segunda parte da definição de cultura tradicional e popular presente na $R e$ comendação para Salvaguarda da Cultura Tradicional e Popular, de 1989. No entanto, cumpre perguntar em que medida as categorias de cultura popular e patrimônio imaterial são equivalentes e intercambiáveis no ambiente da Unesco e nas políticas culturais adotadas em países como o Brasil.

É possível encontrar pistas para se perceber como essas categorias tornaram-se intercambiáveis e assumiram efeitos práticos bem próximos no âmbito das práticas discursivas da Unesco nos próprios documentos e atos jurídicos da organização. Em 2001, foi publicada pela Unesco a Lista de Obras Primas do Patrimônio Oral e Intangível da Humanidade. Os critérios de inclusão na lista, de acordo com o Conselho Consultivo da Unesco, seguem as justificativas de que os bens que nela figuram possuem uma "expressão cultural tradicional e popular de excepcional valor do ponto de vista histórico, artístico, etnológico, antropológico, lingüístico ou literário" (Unesco, 2001). 85\% dos bens contemplados na lista foram inscritos de acordo com esses critérios e pertencem às chamadas culturas tradicionais e populares dos continentes asiático, africano e latino-americano.

A lista, no entanto, foi constituída a partir da criação, no âmbito da Unesco, de um programa de valorização dos chamados mestres de arte, considerados os grandes portadores dos saberes, dos fazeres, das memórias orais, das celebrações, entre outros (Unesco, 2001). O programa foi intitulado pela organização, em 1996, de Tesouros Humanos Vivos da Humanidade. Seguindo as recomendações do Conselho Consultivo da organização, no decurso dos anos noventa, alguns países membro passaram a implementar ações no sentido de assegurar aos chamados mestres de arte as condições de transmissão do acervo de saberes e fazeres às novas gerações (Unesco, 1996). Buscando sistematizar uma linha de ação nessa seara, ainda em 1993 o Conselho Consultivo da Unesco definiu o patrimônio cultural imaterial ou intangível nos seguintes termos: 
O conjunto das manifestações culturais, tradicionais e populares, ou seja, as criações coletivas, emanadas de uma coletividade, fundadas sobre a tradição. Elas são transmitidas oral e gestualamente, e modificadas através do tempo por um processo de recriação coletiva. Integram esta modalidade de patrimônio as línguas, as tradições orais, os costumes, a música, a dança, os ritos, os festivais, a medicina tradicional, as artes da mesa e o saber fazer dos artesanatos e das arquiteturas tradicionais (Unesco, 1993).

Pode-se notar que o conceito acima, cunhado pelo Conselho Consultivo da Unesco em 1993, é bastante semelhante ao segundo registro conceitual destacado antes na definição de cultura tradicional e popular presente na Recomendação para Salvaguarda da Cultura Tradicional e Popular, de 1989, assim como é bastante próxima ao segundo registro conceitual contido na definição do patrimônio cultural imaterial, presente na Convenção para Salvaguarda do Patrimônio Cultural Imaterial, de 2003. Salta aos olhos, em todos esses documentos e suas definições de cultura popular e patrimônio imaterial, a presença da noção de tradição. Na definição acima, a referência à noção de tradição aparece cinco vezes, uma repetição significativa. Talvez seja através da noção de tradição, sua carga ética e valorativa, que as categorias de cultura popular e patrimônio imaterial vêm assumindo formas de equivalências. Muitos autores buscam explorar as aproximações entre as categorias de cultura popular e patrimônio imaterial a partir da constituição dos diferentes olhares intelectuais-científicos e dos lugares institucionais de fala em que esses olhares são engendrados e institucionalizados. Isabela Tamaso produz uma síntese bastante elucidativa acerca dessas aproximações. Buscando entender as implicações epistemológicas e profissionais para a antropologia e para os antropólogos diante da institucionalização do patrimônio cultural imaterial e de sua conversão em objeto de direito internacional, Tamaso destaca:

Uma diferença há e não é de objeto, mas sim epistemológica. Transformase o modo como se olha para o objeto. Manifestações culturais (danças, músicas, poesia, crença, expressões, técnicas, etc.), olhadas por folcloristas são "folclore", "fato folclórico", "manifestação folclórica”. Aos olhos dos antropólogos, são cultura e/ou cultura popular. Atualmente a tendência de ambos é de percebê-los como patrimônio; ao menos pelo fato de que, ao serem potencialmente bens patrimoniais ampliam as possibilidades profissionais de ambos (Tamaso, 2006: 11).

Autores como Marina Mello e Souza, Sandra Pelegrini e Pedro Paulo Funari compartilham das observações de Tamaso. Cecília Londres assinala que a dilatação na noção de patrimônio dependeu fundamentalmente de uma aproximação, iniciada no Brasil nos anos setenta, entre antropologia e as políticas culturais, notadamente nas áreas de patrimônio e cultura popular (Londres, 2003: 20). 
Acerca das relações entre o Brasil e a Unesco por ocasião da consecução da convenção do patrimônio imaterial e da definição de patrimônio cultural imaterial, o representante da Unesco no Brasil, Vincent Defourny, sustenta: "pode se dizer que a sintonia de ordem conceitual entre as posições da Unesco e as posições do Brasil neste campo é tão fina, que a experiência brasileira passa a ser destacada no âmbito do processo de elaboração da própria convenção, que incorpora seus princípios gerais" (Defourny, 2008: 7). Marina Mello e Souza observa que os bens registrados no Brasil e em outras partes do mundo, sob a rubrica de patrimônio cultural imaterial, têm sido selecionados a partir daquilo que é considerado como tradicional e reputados como representativos das identidades nacionais e/ou regionais pelos grupos político-culturais ocupados com o tema do patrimônio cultural imaterial (Souza, 2001). Assim, na mesma direção de Tamaso, Souza indaga:

\begin{abstract}
Nesse conjunto de manifestações, cabem aquelas realizadas pelas classes dominantes, ligadas à chamada cultura erudita, ou apenas as produzidas pelas camadas populares? Cabem as inovações contemporâneas, o rap, o artesanato de material industrial reciclado, o resultado de intervenções eruditas junto a grupos populares, ou apenas aquilo que se liga a tradições reconhecidas enquanto tal, seja pela longevidade, seja pela sólida aceitação dentro do grupo que a realiza? Não sei se por causa do viés da minha formação, mas, no meu entender, o que hoje se chama de patrimônio imaterial é o que há vinte anos chamávamos de cultura popular. De qualquer forma, é dentro dessa perspectiva que venho abordando a questão (Souza, 2001: 142).
\end{abstract}

Maria Laura Viveiros de Castro Cavalcante, por seu turno, assinala que o conceito de patrimônio cultural imaterial no Brasil é dotado de um forte viés antropológico, abarcando potencialmente as expressões de todos os grupos e camadas sociais, mas verifica-se no país a tendência de seu entendimento e sua aplicação aos ricos universos das culturas tradicionais populares e indígenas (Cavalcanti, 2008: 12).

Chancelando as indagações e observações dos autores mobilizados no Brasil, por exemplo, as primeiras ações dirigidas ao registro dos bens considerados patrimônio cultural imaterial, efetivadas a partir da instituição do Decreto $\mathrm{n}^{\circ}$ 3.551/00, que também instituiu o Programa Nacional do Patrimônio Imaterial (PNPI), foram realizadas e coordenadas pelo Centro Nacional de Folclore e Cultura Popular (CNFCP). Em 2005, a Revista Encontros e Estudos, publicação periódica do CNFCP, trouxe no seu sexto volume um balanço sobre as ações de registro do patrimônio imaterial. Na publicação, intitulada Registro e Políticas de Salvaguarda para as Culturas Populares, os pesquisadores do centro analisam e descrevem os registros realizados pela instituição, como o ofício das paneleiras 
de Goiabeiras, no Espírito Santo; o Círio de Nazaré, em Belém, no Pará; o Samba de Roda, na Bahia; o ofício das baianas de Acarajé, também na Bahia; e a violade-cocho, no Mato Grosso e Mato Grosso do Sul. Esses bens foram inventariados e registrados no âmbito da PNPI a partir da experiência piloto coordenada pelo CNFCP de 2001 a 2006, período em que vigorou o projeto Celebrações e Saberes da Cultura Popular (CNFCP/IPHAN, 2006).

Esse emaranhado de formações conceituais, que compõem uma verdadeira rede semântica, tem sido manejado e remanejado, promovendo aproximações e distanciamentos discursivos e efeitos políticos também intercambiáveis. Por exemplo, embora o movimento folclórico constitua um vetor decisivo de formação das políticas culturais públicas para as chamadas culturas populares no Brasil, o termo/categoria folclore sofreu um deslocamento significativo, quase uma anulação. A categoria, por exemplo, não aparece nas justificações e formulações do Programa Nacional do Patrimônio Imaterial (PNPI/IPHAN). Uma das pistas para se compreender esse processo de deslocamento e/ou limpeza semântica está no trabalho de Rodolfo Vilhena, notadamente no que diz respeito às lutas institucionais e profissionais envolvendo os pesquisadores folcloristas e os cientistas sociais (Vilhena, 1997: 176).

Seguindo essa seara, Sydnei Limeira Sanches assinala que o termo folclore não é bem aceito pelos organismos transnacionais, por isso o termo/categoria não aparece no texto das convenções, é entendido como algo menor ou pejorativo. "Por conta de tal resistência a Unesco vem abandonando a expressão "folclore" em favor do termo "patrimônio cultural imaterial". O mesmo acontece com a OMPI (Organização Mundial da Propriedade Intelectual) que vem adotando o termo "expressões culturais tradicionais" em substituição ao "folclore"(Sanches, 2008: 57).

Importa acentuar, contudo, como se mencionou antes, que tanto a categoria de cultura popular como a categoria de patrimônio imaterial devem seu poder de significação e o próprio movimento mútuo de aproximação à maneira como são utilizadas e manejadas por governos nacionais e organizações transnacionais para justificar as políticas culturais contemporâneas. Um dos grandes elos de aproximação entre a categoria de cultura popular e patrimônio cultural imaterial é fornecido, como se viu, pela presença discursiva e valorativa da categoria de tradição. Não obstante, todas essas categorias formam um repertório discursivo, manejado e remanejado a partir do apelo global à diversidade.

Mais do que um tema, a diversidade passou a ser um valor mobilizador, capaz de catalizar e municiar grupos político-culturais em todo o mundo, como as coalizões globais destacadas por Mckee e as organizações citadas por Mattelart. Cultura popular e patrimônio imaterial passaram a figurar, tanto nos documen- 
tos e tratados internacionais quanto nos relatórios de avaliação e gestão das políticas culturais nacionais, como as principais fontes da diversidade cultural. Essas categorias/valores (cultura popular, patrimônio imaterial e tradição) tornaram-se, por um lado, recursos simbólicos e políticos para se falar e justificar o tema/valor da diversidade, por outro, converteram-se em objeto de proteção e promoção, necessários à manutenção e expansão da diversidade (Unesco, 2005). Logo, no segundo ponto de justificação da Convenção para Salvaguarda do Patrimônio Cultural Imaterial aparece a seguinte justificativa:

Considerando a importância do patrimônio imaterial cultural como fonte da diversidade cultural e garantia de desenvolvimento sustentável, conforme destacado na Recomendação da Unesco sobre a Salvaguarda da Cultura Tradicional e Popular, de 1989, como na Declaração Universal da Unesco sobre a diversidade Cultural, de 2001, e na Declaração de Istambul, de 2002, aprovada pela Terceira Mesa Redonda de Ministros da Cultura (Unesco, 2003).

Grande parte da malha conceitual, discursiva e jurídica apresentada até aqui foi tecida tendo em vista os interesses das elites intelectuais-científicas nacionais e transnacionais incumbidas de interpretar os processos sociais contemporâneos (sobretudo a produção simbólico-cultural) e confeccionar soluções ou medidas que possam dirimir as muitas tensões e antagonismos. Com efeito, boa parte dessas operações discursivas foram feitas no sentido de acomodar as antigas antinomias existentes entre as categorias de cultura e desenvolvimento. Ao fazê-las, agências transacionais, como a Unesco, e os governos nacionais, como o governo brasileiro (ambos pressionados por uma multiplicidade de organizações e grupos político-culturais globais), produziram uma dilatação significativa na categoria cultura, que, por seu turno, produziu também uma dilatação na categoria de desenvolvimento.

Essas observações não significam, contudo, que as elites intelectuais-científicas mencionadas tenham produzido essas categorias e suas aproximações teóricas e semânticas a partir de um cálculo, movido por um objetivo pré-estabelecido e pela intencionalidade de um único agente social. Antes o contrário, esses objetivos foram surgindo à medida que pressões políticas ganharam legitimidade global e categorias que sintetizam valores coletivos - como cultura tradicional e popular, patrimônio cultural imaterial e diversidade cultural - converteram-se em dispositivos jurídicos internacionais, com força de lei e densidade ético-moral. Em uma palavra, a cristalização dos valores que essas categorias expressam e sua respectiva oficialização no âmbito do direito internacional dependeram de um conjunto de lutas político-culturais, que desencadearam verdadeiras guerras simbólicas. 
Uma das principais implicações do processo de dilatação do conceito de cultura e da publicação dos instrumentos jurídicos aludidos antes foi a criação de duas categorias de direitos culturais conjugados, ambas inscritas no mesmo movimento responsável pela dilatação do conceito de desenvolvimento, que foi, simultaneamente, resultado e condição para a expansão discursiva e operacional do conceito de cultura. As categorias são as seguintes: por um lado - baseado no longo percurso de valorização e respeito à diferença, à identidade e à diversidade percorrido pela Unesco -, todas as culturas têm o direito de serem o que são, ou seja, de manterem seus costumes, tradições e crenças; por outro lado, essas mesmas culturas, os grupos culturais e os indivíduos têm o direito de adquirem novos hábitos, costumes e tradições, ou seja, de adquirirem novas e variadas formas de cultura. Essa última categoria engendra, com efeito, toda uma discussão em torno do acesso aos bens e serviços culturais e abre, por assim dizer, todas as janelas e portas que levam ao consumo cultural, à fruição estética e ao acúmulo de novas experiências simbólicas.

Essas duas categorias de direitos passaram a aparecer conjuntamente nos documentos e instruções normativas da Unesco, não sem suscitar uma miríade de ambivalências e a conviver sob o signo de um equilíbrio instável, um arranjo que pode ser desfeito ao sabor das circunstâncias. Por exemplo, a segunda categoria de direito mobilizada pode ser entendida como um desdobramento das transformações nos fluxos comunicacionais e da profusão dos bens e serviços culturais, que, entre outros aspectos, corroboraram para a consolidação de uma economia pós-industrial baseada nos serviços (Bell, 1973: 87). Os direitos culturais, estabelecidos e assegurados nos artigos 215 e 216 da Constituição Federal de 1988, passaram a ser acionados e operacionalizados como aspectos específicos das políticas culturais dentro da chave discursiva envolvendo as novas relações entre cultura e desenvolvimento. Um exemplo claro a esse respeito foi a publicação do documento Políticas Culturais Para o Desenvolvimento, elaborado pela Unesco em parceria com instituições brasileiras, cuja origem remonta ao Seminário Internacional Sobre Políticas Culturais para o Desenvolvimento, promovido pela Unesco e pelo IPEA, realizado em Recife/PE, em agosto de 2003. No documento, que traz recomendações e reflexões especificas para o Brasil e América Latina, aparecem nomes como Nestor Garcia Canclini, George Yúdice e Teixeira Coelho, além de outros pesquisadores e críticos culturais. Logo na apresentação, feita pelo então ministro da cultura Gilberto Gil, surgem com tintas vivas e precisas as novas relações entre cultura e desenvolvimento:

A relação entre cultura e desenvolvimento vem assumindo, crescente e aceleradamente, um lugar de destaque na agenda contemporânea. Está claro que, nessa perspectiva, falamos de cultura no seu conceito mais pleno. Cultura, portanto, como a dimensão simbólica da existência social de 
cada povo, argamassa indispensável a qualquer projeto de nação. Cultura como eixo construtor das identidades, como espaço privilegiado de realização da cidadania e da inclusão social e, também, como fator econômico gerador de riquezas. (Gilberto Gil, 2003).

A fala do ex-ministro é esclarecedora para se compreender a operacionalização das novas políticas culturais a partir da dilatação do conceito de cultura. 0 conceito de cultura, a partir das transformações discursivas sofridas nos anos oitenta e noventa (boa parte delas em decorrência das transformações socioeconômicas ocorridas nos anos setenta), passa a ser operacionalizado no decurso dos processos de elaboração, execução e avaliação das políticas culturais, que passam a surgir na América Latina, África e Ásia. Ao se tornar objeto de políticas de Estado, como uma área ministerial específica (distinto do que ocorria até o início dos anos oitenta) a cultura passa a ser objeto do disciplinamento e da racionalização técnico-administrativa das burocracias de Estado.

Com efeito, as políticas culturais contemporâneas passaram a abrigar, não sem tensões, as incorporações e dilatações experimentadas no conceito de cultura nas últimas três décadas. A categoria cultura passa a ser mobilizada a partir do imperativo de se formular políticas de Estado para a cultura que, necessariamente, deveriam incorporar três dimensões constitutivas: a chamada dimensão simbólica (como atesta a fala do ministro), que está ligada à ideia de cultura como uma totalidade de crenças, hábitos e formas de reconhecimento (trabaIhada pela Unesco em torno dos pilares da identidade, da diferença e da diversidade); a dimensão econômica, que está ligada à geração de trabalho, emprego e renda e, portanto, à produção de bens e serviços culturais; e a dimensão legal, que envolve as duas categorias de direitos culturais destacadas antes e que no Brasil recebe a designação de cidadania cultural (MINC, 2006). Já a categoria desenvolvimento aparece como a realização de duas dimensões: o desenvolvimento econômico, que, embora tenha perdido parte do seu status, continua sendo importante, ainda mais porque está ligado à geração de trabalho, emprego e renda; e o desenvolvimento humano e/ou social, esse sim, grande meta das políticas culturais para o desenvolvimento.

\section{Considerações Finais}

Certamente a conformação dos princípios que conduzem hoje a um universalismo global, que galvaniza, numa mesma moeda ético-moral, diversidade e identidade local, não foi resultado das convenções publicadas pela Unesco nesta década. Esse processo já vem se erigindo desde a criação da organização após a Segunda Guerra Mundial, em 1946. Não obstante, as interdependências sociopolíticas forjadas a partir dos anos setenta pressionaram sobremaneira 
a Unesco no sentido da adoção de ações destinadas à proteção e promoção dos conteúdos das culturas populares e/ou tradicionais. Essas medidas, como a declaração para Salvaguarda das Culturas Tradicionais e Populares, publicada em 1989, constituem a gênese de formação das convenções publicadas nesta década, que ergueram um marco de inspiração normativa para elaboração e execução das políticas culturais na contemporaneidade. Segundo essa senda, percebe-se que um dos vetores causais, mencionado no início do texto, que derivou para o advento desse universalismo ancorado na diversidade cultural, encontrou as condições de possibilidade operacionais a partir expansão dos mercados de consumo culturais globais: cinematográfico, editorial, musical, entre outros. Essa profusão de bens e serviços simbólico-culturais encetou, no horizonte do trabalho político, uma série de reações às ameaças, sempre iminentes, de homogeneização, estandardização dos universos simbólicos e dos códigos identitários. Segundo Alfredo Manervy, as convenções e declarações publicadas pela Unesco constituem o Protocolo de Kyoto da cultura ${ }^{5}$. A assertiva do secretário deixa entrever como a Unesco, sobretudo no que tange à cultura, atua como agente transnacional moralizador, devotado à produção e expansão de princípios éticos universalizantes, como, por exemplo, o valor conferido à noção de diversidade cultural.

Abstract: This article attempts to situate the emergence and development of a discursive formation responsible for the appearance of a new global universalism. The ethical and moral imperative of this universalism is the defense and promotion of values such as cultural diversity. To understand the political and cultural implications of this universalism, this article elects as its empirical axis the performance of the United Nations Educational, Scientific and Cultural Organization (UNESCO), highlighting the actions of the organization in coordinating and facilitating a symbolic and discursive transnational transit involving governments, nongovernmental organizations and political groups.

Keywords: Global universalism; UNESCO; symbolic transit; cultural diversity; intangible heritage and popular culture.

\section{Referências}

BELL, D. (1973) The coming post-industrial society. New York: Basic Books

Castells, M. (2000) O poder da identidade. São Paulo: Paz e Terra.

Cavalcanti, M. L. V. de C. \& Fonseca, M. C. L. (2008) Patrimônio Imaterial no Brasil: legislação e políticas estaduais. Brasília: UNESCO.

Canclini, N. G. (2006) Culturas híbridas. São Paulo: Edusp.
5. A frase foi cunhada pelo hoje secretario executivo do Ministério da Cultura, Alfredo Manervy, durante entrevista concedida no dia 11 de dezembro de 2007, realizada na sede do Ministério da Cultura, em Brasília, Distrito Federal. 
ELIAS, N. (1991) O processo civilizador, Vol I. Rio de Janeiro: Jorge Zahar Editor.

Castels, M. (2003) O poder da identidade. São Paulo: Record.

DuPIN, G. (2008) “O governo brasileiro e a diversidade cultural”, In Barros, J. M. de B. (org.), Diversidade cultural: da proteção à promoção. Brasília: Autêntica/ Observatório da Diversidade Cultural.

FOUCAULt, M. (1986) Arqueologia do saber. Rio de Janeiro: Forense.

FunARI, P. P. A. (2008) O que é patrimônio cultural imaterial. São Paulo: Brasiliense.

MatTlaRt, A. (2005) Diversidade cultural e mundialização. Parábola: São Paulo.

MoRAES, G. (2006) Diversidade cultural e convenção da UNESCO. Brasília: Coalizão brasileira pela diversidade cultural.

TAMASO, I. (2005) Novos olhares sobre velhos objetos: outros desafios. Sociedade e cultura, Vol 8, n 2.

UNESCO E MinISTÉRIO DA CULTURA (2008) Patrimônio imaterial: política e instrumentos de identificação, documentação e salvaguarda. Brasília.

. (2003) Convenção Para Salvaguarda do Patrimônio Cultural Imaterial. Paris.

. (2005) Convenção Para Proteção e Promoção da Diversidade das Expressões Culturais. Paris.

. Recomendação Sobre a Salvaguarda da Cultura Tradicional e Popular (1989). Paris.

. (2008) Caderno de Conservação e Restauro de Obras de Arte de Popular Brasileira. Rio de Janeiro. . (2000) Informe mundial sobre a cultura: diversidade cultural, conflito e pluralismo. São Paulo: Moderna 